\title{
Critical Thinking of Female Students in Solving Mathematical Problems
}

\author{
Riny Arviana ${ }^{1 *}$, Sufyani Prabawanto ${ }^{2}$ \\ 1,2 Universitas Pendidikan Indonesia \\ ‘riny.arviana@upi.edu
}

\begin{abstract}
Higher order thinking skill is a topic which attracts more attention of researchers in education field. Critical thinking belongs to higher order thinking skills. This kind of thinking should be had by everyone. Critical thinking belongs to 21st century skills Solving real world-mathematical problem regularly is assumed as one of ways encouraging one to grow and to enhance his critical thinking. A person who has good critical thinking skill in solving mathematical problems is considered to also think critically well in living his daily life. This study aims to investigate the critical thinking skill of female students consisting of ability in giving argument, drawing conclusion, and evaluating conclusion. A case study was carried out to four female students who were recruited based on their volunteering. Their critical thinking skills were evaluated by using essay test and interview. Participants' critical thinking in solving mathematical problems is classified into high, medium, or low level. FS-1 and FS-4 are classified as low-level critical thinker. FS-2 and FS-3 are classified as high-level critical thinker. It is recommended to conduct similar study with larger sample involving both male and female students to compare their critical thinking in solving mathematical problems.
\end{abstract}

Keywords: critical thinking, mathematical problem, female, case study

\section{Introduction}

Human life always encounters various developments. Not only in technology, but also in culture, social, economic, science, even education sector. It cannot be denied that these developments put people to deal with the new challenges and problems. Knowing this fact, then having the higher order thinking skills is a must for everyone. One of higher order thinking skills is thinking critically. Thinking critically is important for each areas of the helping professions, including practice, research, policy, administration, and advocacy (Gambrill \& Gibbs, 2017). Thinking critically is not similar with ordinary or routine thinking. Both of them are different principally. In routine thinking, we are not always in conscious condition. We also do not give much effort to answer the asked questions. For instance, when we came to one's house and were asked by host to choose between tea and coffee, we can answer this question easily. Meanwhile, critical thinking is much more complicated than routine thinking. Critical thinking is a process of comprehensive thinking in which sometimes the thinker judges the quality of his own thinking (Arviana, 2018). A critical thinker raises vital questions and problems, and then formulates them clearly, gather and assess relevant information, use abstract ideas, think open-mindedly, and communicate effectively with others (Song, 2016).

The term 'critical thinking' has been tried to be defined by many researches, as well as the reason why it should be taught and how to teach it. Early definition of critical thinking was 
proposed by Bloom as critical thinking is the mastery of a set of skills such as knowledge, comprehension, application, analysis, synthesis, evaluation, and applying the best when faced with a novel situation in which three higher levels, i.e. analysis, synthesis, and evaluation, are frequently reported to reflect critical thinking (Fahim \& Eslamdoost, 2014). Critical, criticism, and critic, all of them originate from the ancient Greek word kritikos which means able to judge, discern, or decide (Butterworth \& Thwaites, 2013). So, why should people have critical thinking skill? The ultimate objective is to come to conclusions that are correct and to make decisions that are wise (Moore \& Parker, 2012). Furthermore, now we live in age of information where there are massive quantities of information available to anyone (Halpern, 2014); either from computer, internet access, or other devices. This fact then requires us to be wise in sorting the information by using critical thinking skill. Critical thinking is an important aspect of 21st century learning (Lombardi, Kowitt, \& Staples, 2015). Solving problems means finding solution. Solving real world-mathematical problem regularly is assumed as one of ways encouraging people to grow and to enhance their critical thinking. Moreover, one of mathematics education objectives is to accustom someone in thinking logically, systematically, creatively, carefully, and critically (Hendriana, Rohaeti, Sumarmo, 2017). This pattern of thinking would help out everyone to be well prepared in encountering the real life where the new problems and challenges will always come over. That is why mathematics cannot be put aside even by someone who has entered the higher education. More mathematical problems being solved by someone means he are getting used to think critically.

College students are part of our society who really needs to have critical thinking skill. In addition to being caused by future career demands, the sheer amount of information in Indonesia is also an excuse. Viral various hoaxes require them to be wise in choosing and sorting out valid information to be accepted. This critical thinking ability is closely related to critical mathematical thinking skill because both refer to the same indicators. A person who has good critical thinking skill in solving mathematical problems is considered to also think critically well in living his daily life. Unfortunately, in fact in there are still many college students who not only do not think critically in solving mathematical problems, but also not being critical in living their daily life. Most of them, especially those from non-math majors, have the perception that mathematics is limited in the fluency of calculating. This was reinforced by an initial interview with several students. They assume that there is no direct impact of learning mathematics on them except eloquence in numeracy. This is of course not true because learning mathematics can also shape a person's mindset to be critical, both in speech and attitude. Therefore, it is not surprising why the college students are also often caught up with the hoax circulating in the midst of society. Female college students were samples selected by researcher in this study. This was based on certain consideration. There exists the assumption that women who tend to endorse gender stereotypes tend to endorse their mathematical abilities (Spencer, Steele, \& Quinn, 1999). This is used to be called stereotype threat. Stereotype threat has been shown to negatively impact women's performance in several contexts, especially in mathematics (Kapitanoff \& Pandey, 2017). Although the belief that men are better at mathematics than women has been repeatedly disproven (Hyde, Lindberg, Linn, et al., 2008), this gender stereotype continues to burden women. This was assumed to influence the critical thinking skill of women too.

Critical thinking skill can be indicated through several indicators. Glaser listed the abilities that indicate the critical thinking skill (Fisher, 2001). Those indicators involving ability: to recognize problems; to find workable means for meeting those problems; to gather and 
marshal pertinent information; to recognize unstated assumptions and values; to comprehend and use language with accuracy, clarity, and discrimination; to interpret data; to appraise evidence and evaluate statement; to recognize the existence of logical relationships between propositions; to draw warranted conclusions and generalizations; to put the test to the generalizations and conclusions at which one arrives; to reconstruct one's pattern of beliefs on the basis of wider experience; and to render accurate judgments about specific things and qualities in everyday life. Meanwhile, Butterworth \& Thwaites (2013) classified the indicators of critical thinking into three, i.e. ability in giving argument, ability in drawing conclusion, and ability in evaluating conclusion. A critical thinker, as Lau (2011) stated, is someone who is able to understand the logical connections between ideas; formulate ideas succinctly and precisely; identify, construct, and evaluate arguments; evaluate the pros and cons of a decision; evaluate the evidence for and against a hypothesis; detect inconsistencies and common mistakes in reasoning; analyze problems systematically; identify the relevance and importance of ideas; justify one's beliefs and values; and also reflect and evaluate one's thinking skills. Indicators of critical thinking which were proposed by Watson \& Glaser (1980), Butterworth \& Thwaites (2013), and Lau (2011) seem similar each other. In this case study, the researcher used three indicators proposed by Butterworth \& Thwaites (2013) because those three are tend to be summary of the others. Thus, the indicators of critical thinking used in this study are the ability in giving argument, drawing conclusion, and evaluating conclusion. Giving argument means one's ability in explaining his ideas clearly and systematically. Drawing conclusion refers to one's ability in making rational decision based on the given information. Evaluating conclusion is related to analyze, identify logical consequences, and evaluate the given arguments.

As we know, critical thinking has been an impressive topic to be studied. Franco, Costa, \& Butler (2017) had conducted a study focusing on critical thinking. In their exploratory study, a sample of 230 first-year students of a Bachelor's Degree or a Master's Degree in Portugal completed an experimental Portuguese version of the Real-World Outcomes, a self-report inventory measuring everyday negative life events that are mediated by a lack of critical thinking. Result of their study presents six types of negative life events resulting from a lack of critical thinking: health neglect, mismanagement, slackness, poor impulse control, academic negligence, and rashness. Meanwhile, Kettler (2014) investigated the critical thinking skills of fourth-grade students from a school district in Texas, including 45 identified gifted students and 163 general education students. Critical thinking scores of these samples did not differ significantly, nor were differences in scores associated with length of exposure to the gifted education program. Chukwuyenum (2013) also conducted study that examined the impact of critical thinking on performance in mathematics among senior secondary school students in Lagos State. The study revealed that there was a significant difference in mathematics performance test scores among the experimental groups. However, previous studies about critical thinking were used to be either literature reviews or comparisons. Purpose of this study is to investigate the critical thinking skill of female college students in solving mathematical problems. A case study was carried out with four female college students who ranged in age from 18 to 22 years old and were recruited based on their volunteering. Their critical thinking skills were assessed by means of test consisting of three mathematical problems and clinical interview. 


\section{Method}

\section{Participants}

Participants in this study were four female college students who ranged in age from 18 to 22 years old. They were recruited voluntarily. Two of them were first-year bachelor students majoring in primary education and the other two were first-year master students majoring in economics education. They had previously graduated from high school with concentration in social science (50\%), science (25\%), and vocational (25\%). In the current education system of Indonesia, science itinerary is characterized by more mathematical content, whereas the social science and vocational involve less mathematical content.

\section{Instruments}

To assess participants' critical thinking in solving mathematical problems, the test and nontest were used. The used test is an essay which consists of three mathematical problems. These mathematical problems consecutively represent the indicators of critical thinking involving ability in giving argument, drawing conclusion, and evaluating conclusion. Scores are summed with the highest total scores is 60; score of each problem is 20; higher scores indicate higher critical thinking. The used non-test is a guided interview which was aimed to explore more explanation of participants' answer in solving the given test. Based on the total score, I then classified the participants into high, medium, or low level of critical thinking in solving mathematical problems. It is classified as low level for total score of $0-20$; medium level for total score of 21-40; or high level for total score of 41-60.

\section{Procedure}

For the purpose of this study, qualitative approach was applied. The purpose of this case study was to describe the current situation in detail rather than draw the generalization. All data were collected within a 1-week period. The researcher visited each of participants separately. Participants were given test and non-test by the researcher at their respective residences. Process of data collection took approximately an hour per participant.

\section{Results and Discussion}

This study concerned to critical thinking involving ability in giving argument, drawing conclusion, and evaluating conclusion. Giving argument means one's ability in explaining his ideas clearly and systematically. Drawing conclusion refers to one's ability in making rational decision based on the given information. Evaluating conclusion is related to analyze, identify logical consequences, and evaluate the given arguments. There are four participants in this study. Each of them consecutively is coded by FS-1, FS-2, FS-3, and FS-4. They were given a test consisting of three mathematical problems referring to critical thinking indicators and also were interviewed separately. The first given problem includes the indicator of giving argument. The second given problem includes the indicator of drawing conclusion. The third given problem includes the indicator of evaluating conclusion.

\section{FS-1}

For the first problem, FS-1 was asked to determine the length of a rectangle field which its circumference was given, and its length was twice of its width. She was also asked to give arguments on their answers. FS-1 cannot found the correct answer for this problem. In the process of interview, she said that she has tried to solve it but did not get the answer. She did not know what mistake she had. While I check her answer, its revealed that she used the 
incorrect formula of rectangle circumference. She used the formula of rectangle area. FS-1 not only failed in giving argument for her answer, but also did mistake in identifying the given information. FS-1 then was asked to draw conclusion based on the given information for the second problem. FS-1 gave the incorrect answer for this problem but she thought that she found the correct one. In the process of interview, she said that her answer must be correct because she refered to the certain procedure. FS-1 not only failed in drawing conclusion based on the given information, but also did mistake in calculating. She did not consider whether her answer made sense or not. For the third problem, FS-1 was asked to evaluate the conclusion given. In evaluating conclusion, we need to give the reason and state it clearly and systematically. FS-1 could find the price of the book but she did not state it clearly to evaluate the conclusion. She thought that problem was solved immediately after finding the price of the book. Thus, FS-1 could identify the given information and do calculation correctly. However, she neither use what she has obtained to judge the conclusion nor state the evaluation clearly. Overall score obtained by FS-1 is 20 so that her critical thinking skill in solving mathematical problems is classified into the low level. As Butterworth \& Thwaites (2013) said, the one who cannot answer a question or solve a problem by giving his argument, then he cannot be called as a critical thinker.

\section{FS-2}

FS-2 did better than FS-1 for the first problem. She can find the length of the rectangle field. However, she did not relate her answer to the asked question. She told that she could not give the arguments for her answer. She felt unsure about it. FS-2 could identify the given information to find the answer but she could not give argument. FS-2 did better than FS-1 for the second problem. She can drawed the conclusion based on the given information. She felt confident about her answer. FS-2 could use the given information to draw the conclusion. Differ with FS-1, FS-2 gave the correct answer for the third problem and stated the judgment clearly. Overall score obtained by FS-2 is 50 . It puts her critical thinking skill in solving mathematical problems is classified into the high level.

\section{FS-3}

For the first problem, FS-3 gave not only the correct answer but also her arguments. She felt confidence about her answer. She could find the length of the field by using the given information. She told that there were relations between the circumference, the length, and the width of a rectangle. FS-3 could identify and use the given information to find the solution along with the arguments. FS-3 did much better than other participants for the second problem. Not only draw the conclusion but she also explains the conclusion clearly. She felt confidence about her answer too. FS-3 could identify and use the given information to draw the conclusion and explain it clearly. For the third problem, P3 could find the price of a book and use it to evaluate the given conclusion. She could identify the given information, do calculation correctly, and evaluate the given conclusion by stating it clearly and systematically. Overall score obtained by FS-3 is 60 so that her critical thinking skill in solving mathematical problems is classified into the high level.

\section{FS-4}

FS-4's answer is the most different of all for the first problem. She left the answer sheet blank. While be interviewed, she told that she really did not have any idea about the problem. She said that she did not want to solve the problem and chose to give up at all without effort. It seems that FS-4 not only has problem with critical thinking, but also with her beliefs system. 
For the second problem, FS-4 did better than for previous problem. FS-4 could use the given information to draw the conclusion. FS-4 also solved the third problem well. She could find the price of a book and use it to evaluate the given conclusion. Thus, FS-4 could identify the given information, do calculation correctly, and evaluate the given conclusion by stating it clearly and systematically. But overall score obtained by FS-4 is 40 so that her critical thinking skill in solving mathematical problems is classified into the low level.

Table 1. Participants' Test Score

\begin{tabular}{lrrrr}
\hline \multirow{2}{*}{ Participant } & \multicolumn{3}{c}{ Score } & \multicolumn{1}{c}{$\begin{array}{c}\text { Total } \\
\text { Score }\end{array}$} \\
\cline { 2 - 4 } & Problem 1 & Problem 2 & Problem 3 & 20 \\
\hline FS-1 & 0 & 5 & 15 & 20 \\
FS-2 & 10 & 20 & 20 & 50 \\
FS-3 & 20 & 20 & 20 & 60 \\
FS-4 & 0 & 20 & 20 & 40 \\
\hline
\end{tabular}

In this case study, it is revealed that each of observed participants has different level of critical thinking skill, especially ability in giving argument, drawing conclusion, and evaluating conclusion (see Table 1). Referring to their test answer and explanation along interview process, it is known that critical thinking skills of FS-1 and FS-4 in solving mathematical problems are classified as low level. FS-1 were not success, neither in giving argument, in drawing conclusion, nor in evaluating conclusion. Critical thinking skills of FS-2 and FS-3 in solving mathematical problems are classified as high level. FS-3 could solve all given problems well, but FS-2 could not. FS-4 could not solve the first problem which involves the indicator of ability in giving argument well. People who able in giving arguments will attempt to provide reasons for thinking. All arguments have two parts. The first part is the reasons and the second part are the belief that those reasons are intended to support (Rainbolt \& Dweyer, 2012).

Furthermore, FS-2, FS-3, and FS-4 success in drawing conclusion based on the given information while FS-1 not. She not only failed in drawing conclusion based on the given information, but also did mistake in calculating. As we know, the conclusion is often marked by the word 'so' or its equivalent. Alternatively, the conclusion may be followed by 'because' or its equivalent to indicate that a reason is being given to support a claim. Butterworth \& Thwaites (2013) stated that in drawing conclusion, people will apply the principle of clarity which makes the best sense as a conclusion. The last given problem is related to ability in evaluating conclusion. It can be said that FS-2, FS-3, and FS-4 did it well. They could evaluate the conclusion by giving the supporting reason and stated it clearly. However, FS-1 did not complete her answer. She did not make relation between her numeric calculation with the final judgment. In evaluating conclusion, people will identify logical consequences and inconsistency to obtain clarification supported by certain reason (Lau, 2011).

For FS-1 and FS-4, based on interview result, it was revealed that they tend to state that they are not confidence about their performance in solving mathematical problems. They said that they were afraid that they will do mistake. They thought that they are not so good in performing mathematics ability. They also said that women are dilligent in learning something but difficult in understanding something and it was contrary to men. Their point of view which encouraged them in performing not good critical thinking in solving mathematical problems, I thought, was influenced by the existence of stereotype threat about gender. Stereotype threat refers to a process in which negative stereotypes associated with individuals' identities lead 
them to expect that an unfavorable evaluation will be made of them (Steele \& Aronson, 1995). These expectations (Steele, 2010) then can act as a threat to the integrity of one's self-image, resulting in harmful consequences including poor self-esteem, self-imposed isolation, inability to focus mentally, and academic underperformance.

\section{Conclusion}

Critical thinking will always be an interesting topic to be discussed. Critical thinking skill is essential for all sorts of careers in which we have to communicate ideas, analyze, solve problems, and make decisions. Solving real world-mathematical problems is assumed as one of ways to grow and to enhance one's critical thinking. Critical thinking would help out everyone to be well prepared in encountering the complicated daily life. That is why the mathematics cannot be put aside. While students practice more in solving mathematical problems, they are getting used to think critically. College students are part of our society who really needs to have critical thinking skill. A person who has good critical thinking skill in solving mathematical problems is considered to also think critically well in living his daily life. Female college students were samples selected by researcher in this study. This research is a case study concerning the critical thinking of female college students in solving mathematical problems. The assessed indicators in this study are ability in giving argument, drawing conclusion, and evaluating conclusion. Ability in giving argument means ability in explaining the ideas clearly and systematically. Drawing conclusion refers to ability in making rational decision based on the given information. Meanwhile evaluating conclusion is related to analyze, identify logical consequences, and evaluate arguments.

Each of observed participants has different level of critical thinking skill, especially ability in giving argument, drawing conclusion, and evaluating conclusion. Referring to their test answer and explanation along interview process, it is known that critical thinking skills of FS-1 and FS4 in solving mathematical problems are classified as low level. Meanwhile, critical thinking skills of FS-2 and FS-3 in solving mathematical problems are classified as high level. FS-1 were not success in giving argument, in drawing conclusion, and in evaluating conclusion. FS4 failed only in giving argument. FS-3 could solve all given problems well which means she was good in giving argument, drawing conclusion, and evaluating conclusion. FS-2 could not give the argument clearly. FS-1 and FS-4 encountered the condition in which they were not confident, either with their answer or with their ability in solving mathematical problem. However, the result of this study cannot be generalized. It is strongly recommended to conduct a similar study with larger sample and using other methods than case study. Furthermore, I recommend conducting the similar study which involves both male and female college students as samples. Hence, we could either determine or do comparison between critical thinking of female and male college students in solving mathematical problems.

\section{Acknowledgments}

Our thanks to Indonesia Endowment Fund for Education of Indonesian Republic (LPDP RI) for supporting this research.

\section{References}

Arviana, R. (2018). Problem Based Learning in Mathematics Education and Its Effect on Students' Critical Thinking. Advanced Science Letter, 24(1), 211-213. https://doi.org/10.1166/asl/2018.11962 
Butterworth J., Thwaites, G. (2013). Thinking Skills: Critical Thinking and Problem Solving. Cambridge: Cambridge University Press.

Chukwuyenum, A. N. (2013). Impact of Critical thinking on Performance in Mathematics among Senior Secondary School Students in Lagos State. Journal of Research \& Method in Education, 3(5), 18-25.

Fahim, M., Eslamdoost, S. (2014). Critical thinking: Frameworks and models for teaching. English Language Teaching, 7(7), 141-151. https://doi.org/10.5539/elt.v7n7p141

Fisher, A. (2001). Critical Thinking: An Introduction. Cambridge: Cambridge University Press.

Franco, A. R., Costa, S., Butler, H. A. (2017). Assessment of Undergraduates' Real-World Outcomes of Critical Thinking in Everyday Situations. Psychological Reports, 120(4). https://doi.org/10.1177/0033294117701906

Gambrill, E., Gibbs, L. (2017). Critical Thinking for Helping Professionals: A Skill-Based Workbook Fourth edition. New York: Oxford University Press.

Halpern, D. F. (2014). Thought and Knowledge: An Introduction to Critical Thinking 5th edition. Sussex: Psychology Press.

Hendriana, H., Rohaeti, E. E., Sumarmo, U. (2017). Hard Skills dan Soft Skills Matematik Siswa. Bandung: Refika Aditama.

Hyde J. S., Lindberg, S. M., Linn, M. C., Ellis, A. B., Williams, C. C. (2008). Gender similarities characterize math performance. Science, 321, 494-495. https://doi.org/10.1126/science.1160364

Kapitanoff, S., Pandey, C. (2017). Stereotype threat, anxiety, instructor gender, and underperformance in women. Active Learning in Higher Education, 18(3), https://doi.org/10.1177/1469787417715202

Kettler, T. (2014). Critical Thinking Skills Among Elementary School Students: Comparing Identified Gifted and General Education Student Performance. Gifted Child Quarterly, 58(2), https://doi.org/10.1177/0016986214522508

Lau, J. Y. F. (2011). An Introduction to Critical Thinking and Creativity: Think More, Think Better. New Jersey: John Wiley \& Sons Inc.

Lombardi, A. R., Kowitt, J. S., Staples, F. E. (2015). Correlates of Critical Thinking and College and Career Readiness for Students with and Without Disabilities. Career Development and Transition for Exceptional Individuals, 38(3), https://doi.org/10.1177/2165143414534888

Moore, B. N., Parker, R. (2012). Critical Thinking 10 th edition. New York: McGraw Hill Companies, Inc.

Rainbolt, G. W., Dweyer S. L. (2012). Critical Thinking: The Art of Argument. Boston: Wadsworth.

Song, X. (2016). "Critical Thinking" and Pedagogical Implications for Higher Education. East Asia, 33(1), 25-40. https://doi.org/10.1007/s12140-015-9250-6

Spencer, S. J., Steele, C. M., Quinn, D. M. (1999). Stereotype threat and women's math performance. Journal of Experimental Social Psychology, 35, 4-28.

Steele, C. M., Aronson, J. (1995). Stereotype threat and the intellectual test performance of African Americans. Journal of Personality and Social Psychology, 69(5), 797-811.

Steele, C. M. (2010). Whistling Vivaldi: How Stereotypes Affect Us and What We Can Do. New York: W. W. Norton \& Company.

Watson, G., \& Glaser, E. M. (1980). Critical thinking appraisal: Manual. New York: Psychological Corporation. 